\title{
Sensibilidad por el medio ambiente y cristianismo
}

\author{
(Environmental sensitivity \\ and Christianism)
}

\section{JORDI PUIG}

Universidad de Navarra, Pamplona

jpbaguer@unav.es

ORCID: 0000-0001-9401-9623

Resumen. La sensibilidad contemporánea por el medio ambiente forma parte desde hace décadas del conjunto de rasgos culturales crecientes del mundo desarrollado. No llega, en cambio, a ser prevalente en las conductas, como se manifiesta particularmente en múltiples aspectos del consumismo que dañan el medio. En su desarrollo y presencia cultural contemporánea, la sensibilidad ambiental parece de entrada no ir muy de la mano del cristianismo, que viene siendo acusado desde hace décadas, y junto con la tradición judía, de ir en dirección contraria a la que indica esta sensibilidad.

Este artículo se propone presentar y reflexionar sobre siete aspectos entrelazados del valor ambiental que son reconocidos desde múltiples expresiones del ambientalismo, muy diverso de por sí. La sensibilidad ambiental cristiana aprende y descubre, en esos aspectos del valor ambiental compartidos con no cristianos o no creyentes, exigencias descuidadas de su propia vocación. La cultura ambiental contemporánea las pone con mucho acierto ante sus ojos, y reclama una conversión, en los modos de vida y de carácter moral, que llama también a los no cristianos o no creyentes desde su racionalidad y capacidad de compromiso. Al aceptar esa ruta de conversión, el cristianismo discierne la presencia vivificante de Cristo en muchos rasgos de la cultura ambiental. 
El encuentro que así se genera alberga un potencial de comprensión y enriquecimiento recíproco, hacia el respeto de los valores naturales y humanos compartidos.

Palabras clave: Ecología; naturaleza; espiritualidad; materialismo; valor ambiental; alianzas ambientales.

Abstract. Contemporary environmental sensitivity has characterized for decades the emerging culture in the developed world. It is not yet mainstream in influencing behavior at a global level, as the growing environmental impact of consumerism testifies particularly to it. Present day environmental sensitivity seems somehow at odds with Christianism, charged for decades alongside Judaism with major responsibility in the environmental crisis.

This paper explains and discusses on seven interlinked aspects of the environmental value amply recognized across environmentalism. In examining them, Christian environmentalism learns particularly some demands of the Christian vocation that may remain neglected and demand a moral conversion both of Christians and of non-Christians and non-believers. In accepting this demand, the Christian discerns the life-giving presence of Christ in many traits of the environmental sensitivity and culture. This encounter offers grounds for a reciprocal understanding and enrichment of Christians and non-believers or non-Christians, towards the attainment of a wider and deeper respect of environmental and human shared values.

Keywords: Ecology; nature; spirituality; materialism; environmental value; environmental partnerships.

\section{Introducción}

La Unión Internacional para la Conservación de la Naturaleza (UICN, en inglés IUCN) es la red medioambiental más grande y diversa del mundo (IUCN 2019a). En su seno, el Grupo Especialista en Religión, Espiritualidad, Conservación Medioambiental y Justicia Climática, RESPECC, promueve la cooperación y entendimiento, entre religiones e intercultural, en el cuidado del planeta (IUCN 2019b). Se promueve así una alianza que enlaza con el último de los Objetivos de Desarrollo Sostenible adoptados por Naciones Unidas en 2015. RESPECC considera que, de forma singular con la encíclica Laudato si' (Francisco 2015), el liderazgo religioso ha asumido de forma global el compromiso explícito con la conservación y justicia medioambientales.

Este artículo distingue entre un cristianismo sociológico y otro más nuclear. El primero consistiría en las expresiones sociales y opiniones manifiestas prevalentes entre las vidas de los que se consideran y reconocen 
cristianos. Lo nuclear del cristianismo sería lo que cada cristiano -o no cristiano- encarne o manifieste de la vida de Jesús de Nazaret, considerado Dios y hombre desde la fe en Cristo. Se encontraría también donde quiera que aniden verdad, bondad y belleza en la creación. Al cristiano se le reclamaría aprender a discernir, también en la vida y cultura de quienes se manifiestan no cristianos, llamadas y ocasiones de conversión a la verdad natural del mundo, su valor y su belleza, tenidos por el creyente como obra de Dios.

Ante la realidad del daño ambiental y social, Jesús invitaría a descubrir y abrazar comportamientos justos con la naturaleza ambiental y humana, a buscar la armonía y el respeto, con la tierra y fraterna. Con esa conversión respondería el cristiano tanto a la llamada de Jesucristo, como a las exigencias morales de la verdad y valor de lo natural compartidas con el ambientalismo no cristiano. En esta dirección de conversión, encuentro y unidad apunta Laudato si', siguiendo la línea abierta ya por Juan Pablo II (2001) al introducir la expresión conversión ecológica, y por Benedicto XVI (2009).

Al proponer los aspectos del valor ambiental que siguen y constituyen el núcleo de este escrito, se escribe desde una sensibilidad tanto cristiana como enriquecida por quienes no se consideran cristianos. Se ha buscado un lenguaje de encuentro entre los mundos no creyentes y creyentes que configuran inseparablemente la casa cultural del autor, quien la quisiera tan amplia y común como lo es la Tierra para todo ser natural, viviente o humano. Así se procura responder, a la vez, a las alianzas a las que llaman Naciones Unidas y la UICN, y a la respuesta que propone Francisco, en Laudato si'. Se presentan a continuación siete aspectos del valor ambiental, desarrollando la ocasión de encuentro y conversión que ofrecen, de la mano de la sensibilidad ambiental y el cristianismo.

\section{Porque existe, la naturaleza tiene valor}

En 1853 fue derribado el Discovery Tree, una secuoya de más de 1200 años. Su enorme tocón (Figura 1) mide siete metros y medio de diámetro. Permanece en Calaveras Big Trees State Park, en California, Estados Unidos. Para lograr la caída, se aplicaron desde toda la circunferencia del tronco barrenas de 
minería, que taladraron el interior. El derribo no debió de responder a una necesidad apremiante. Algún grabado de la época sugiere un destino inmediato banal (Figura 2).

El suceso ejemplifica las vías que puede tomar el progreso tecnológico y el mal empleo de sus herramientas, o de sus posibilidades. En especial cuando no se detiene ante valores que hoy parecen evidentes al ambientalismo, y transforma sin miramientos la realidad, aunque sea con daño gratuito y evitable. Esta idea de progreso es denunciada hoy por la sensibilidad ambiental (Ramos 1993, 17). Al instrumentalizar la naturaleza lingüística y operativamente, se ha arrancado de la tierra su capacidad de asombrarnos (Macfarlane 2016, 25). Perdido el asombro, se hace más difícil reconocer el valor de lo existente.

¿Cuál es el valor de conservar y fortalecer este sentido de sobrecogimiento y de asombro, este reconocer algo más allá de las fronteras de la existencia humana? ¿Es explorar la naturaleza sólo una manera agradable de pasar las horas doradas de la niñez o hay algo más profundo? Yo estoy segura de que hay algo más profundo, algo que perdura y tiene significado. [...]. Hay una belleza tan simbólica como real en la migración de las aves, en el flujo y reflujo de la marea, en los repliegues de la yema preparada para la primavera. Hay algo infinitamente reparador en los reiterados estribillos de la naturaleza. (Carson 2012)

El ambientalismo detecta que la existencia es un valor en sí. Lo hace, por ejemplo, a través de esa “... belleza tan simbólica como real...” que movía a Carson, considerada la más destacada figura pública del ambientalismo del siglo XX (Scheuering 2004, 61-62). Los seres naturales, por el no tan mero hecho de existir -que con frecuencia se da por descontado- tienen valor. La sensibilidad ambiental ve y acepta que se hable de valor en cada río, árbol, animal, ecosistema o paisaje. No tienen que ser inmensos o excepcionales como el Discovery Tree para merecer ser respetados. "Quisiera que mis escritos condujeran a la gente a pensar no sólo en árboles, como hace ahora la mayoría” cita Macfarlane de Roger Deakin, "sino en cada árbol individual" (Macfarlane 2016, 11-12). “Cada árbol reclama una admiración especial”, escribió John Muir en su diario (Macfarlane 2016, 11). El valor de lo natural 
no nace de una designación humana, que sí puede reconocerlo adaptando la conducta y el uso a los que la justicia con cada ser -la moralidad- exige. Pero, volviendo a Macfarlane, hemos aprendido con tanta eficacia a usar la realidad, que cuesta verla en sí, no como medio. En una dirección similar apuntaba Thoreau, entre muchos otros (Ramos 1993, 59).

"Nuestra capacidad de percibir la cualidad en la naturaleza empieza, del mismo modo que en el arte, con lo bonito. Se expande a través de sucesivas etapas de lo bello hacia valores todavía no capturados por el lenguaje" (Leopold 1966, 96). Lo natural apuntaría, desde su existir, hacia un sinfín que reclama pausa para asomarse a todo su valor. La poesía de lo natural testificaría esta práctica, con su capacidad de mirar y ver con mayor profundidad. El cristianismo, por su parte, revelaría riquezas añadidas. Misteriosamente, más allá de un plano experimentable al uso, Dios mantendría en cada instante por un motivo de amor el "siendo" de cada ser, porque "Dios es amor" (1 Jn 4, 8). En este sentido se puede entender a Francisco: “La naturaleza está llena de palabras de amor...” (Francisco 2015, n. 225). Y siguen a esas palabras algunas razones que impedirían captar esa dimensión de lo real: “... pero ¿cómo podremos escucharlas en medio del ruido constante, de la distracción permanente y ansiosa, o del culto a la apariencia?” (Francisco 2015, n. 225).

\section{Porque existe como es, la naturaleza tiene valor}

El ambientalismo detecta valor en cada expresión de la variedad, como lo indica el empleo de la biodiversidad para resumir la salud de lo natural (CBD 2019). La diversidad en el modo de existir manifiesta una pluralidad de valores, que ofrecen una guía sobre cómo debe ser una conducta respetuosa hacia cada caso: cortar el pelo no implica falta de respeto; cortar la mano, sí. Cabe siempre el riesgo de no saber o no querer ver el valor de cada modo de ser. Relata Watson (2002, 11-12) que Malebranche (París 1638-1715) paseaba por París acompañado cuando se acercó cariñosamente una perra gestante. Se arrodilló para acariciarla y después, asegurándose de que le estaban mirando, pateó con fuerza al animal en su vientre. La perra se alejó corriendo y gimoteando. Los testigos del suceso exclamaron horrorizados. 
Él les respondió, buscando la ocasión de aleccionar: "Conteneos. Esa perra es solamente una máquina”.

El mecanicismo que Malebranche representa despojó -al sentir y entender de hoy- a la vida animal de aspectos irrenunciables de su valor, reduciéndola a un mecanismo que se puede patear. Ocurre algo análogo con la crisis ambiental: no vemos, aprendemos o respetamos lo suficiente el valor del modo de ser de lo natural. Y si es cierto que, de hecho, la humanidad está causando una pérdida creciente de valor ambiental al vivir (United Nations 2019b), ¿cómo evitar el pesimismo antropológico? Porque es notable el contraste entre la riqueza y evolución conocida del mundo dado por sí mismo antes de la aparición del ser humano, y el empobrecimiento o daño causado en particular por el progreso más reciente (Ramos 1993, 54). ¿Qué podría aportar el cristianismo, que se pueda sumar a una respuesta coral, lo más universalmente aceptable posible?

El libro del Génesis relata la harmonía original entre todo lo natural. La armonía es rota (Gen 2,17) con la desobediencia humana a aquél Creador que mantendría la realidad siendo (Punto 1). "Siendo...”, se puede añadir ahora, “...como es”. La actual crisis estaría presente como posibilidad desde la aparición del ser humano. Pero no por su existir, sino porque, por ser libre, puede elegir una conducta dañosa, que de hecho escoge. El problema pasaría, así, de ser existencial a ser moral. Arrancaría en el inicio de los tiempos humanos. Pero con el desarrollo exponencial de la capacidad de transformación de la tierra, a partir de la Revolución Industrial se manifiesta muy particularmente.

La singularidad moral humana, ese ser "como somos" que nos hace libres y capaces de moralidad, explica que solo se pida responsabilidad moral a los humanos. Con ese modo natural de ser habría aparecido el Homo sapiens en el mundo que, por ser y por ser como es, invita al ser humano a respetarlo. En respuesta, éste debería adaptar su conducta al valor de lo no específicamente humano que sustenta su vida, para no causar un daño moralmente evitable. Un daño que no es solamente fáctico o físico, como el de cualquier depredador natural sobre su presa, sino moral originariamente (Punto 7): causado por el exceso o desorden de su voluntad y del beneficio propio. 
Señala Francisco, en relación con lo que se acaba de proponer: "La violencia que hay en el corazón humano, herido por el pecado, también se manifiesta en los síntomas de enfermedad que advertimos en el suelo, en el agua, en el aire y en los seres vivientes." (Francisco 2015, n. 2). El relato del Génesis, de carácter religioso, puede aportar en su propio lenguaje (Francisco 2015, n. 199) una especial penetración en las causas y remedios para los males ambientales contemporáneos. Según este relato, al poco de ser creado, el ser humano ya hizo méritos para ser expulsado del paraíso natural en el que estaba integrado armónicamente en origen, si bien dejado en manos de su propia libertad. La respuesta de los seres naturales, en su conjunto, al maltrato por el que optó habría sido la aparición de la conflictividad entre lo natural humano y lo no humano (Gn 2,19).

Pero la libertad también introduciría, según el cristianismo, la posibilidad de redención, incluyendo la de la tierra (Rom 1, 18-23). El ser humano puede cambiar, convertirse. Y tiene la capacidad de intervenir en la naturaleza de una manera sanadora, enriquecedora, apuntada también por Francisco con prudencia: “Una intervención legítima es aquella que actúa en la naturaleza «para ayudarla a desarrollarse en su línea, la de la creación, la querida por Dios»” (Francisco 2015, n. 112). El camino de la evolución, que testifica un enriquecimiento progresivo de la diversidad de la vida, podría señalar cómo interpretar cuál es esa línea “querida por Dios”: una que enriquece y no reduce el valor. Desde el ambientalismo, Aldo Leopold formuló un principio sintético y exigente de la ética ambiental en este sentido, de la que es notabilísimo representante: "Algo es correcto cuando tiende a preservar la integridad, estabilidad y belleza de la comunidad biótica. Es erróneo cuando tiende a otra cosa” (Leopold 1966, 240).

La posibilidad de aumentar la riqueza natural, o de procurar intencionalmente no disminuirla al menos, es una capacidad natural propia del ser humano. Lo ha ejemplificado un humilde campesino de Burkina Faso. Yacouba Sawadogo ha vencido tierras a la desertización en el Sahel (United Nations 2019). Su aldea se ha beneficiado de su dilatada labor, y su influjo se está extendiendo internacionalmente, con los claroscuros que él mismo 
testimonió (1080 Film \& Television 2012) en un encuentro convocado por Naciones Unidas para combatir la desertización (COP10 2011).

\section{Porque existe como es, en relación natural, la naturaleza tiene valor}

La conciencia ecológica parece hoy sugerir precisamente esto de modo apremiante, en el siguiente sentido: arrancar una cosa natural del lugar en el que se encuentra por naturaleza y en el que puede ser lo que es por naturaleza, para situarla en un contexto de objetivos que le son extraños y exteriores -la mayor parte de las veces al precio de su aniquilación- es algo que necesita siempre ser justificado. (Spaemann 1989, 103)

Una mirada individualizadora, como la que ofrece la visión de una orca en un acuario, puede ayudar a ver el valor de cada organismo como ser único. Pero ahí no se acaba su valor. El que expresa su integridad corporal en el acuario no debe hacer olvidar el que manifiesta su existencia natural en el océano. La integración en su medio natural se realiza precisamente a través de ese cuerpo que la individualiza, pero que -se afirma- no debería aislarla en un acuario.

"Cuando uno intenta recoger algo por sí mismo, lo encontramos amarrado a todo lo demás que existe en el Universo”, escribió Muir (1911, en “27 de julio”). La ciencia ecológica alimenta la percepción de esa conexión. Pero por múltiples razones, la cultura tiende a subrayar en exceso una conexión o relación muy concreta, en detrimento de las demás que hilvanan el todo integrado: el interés para el ser humano. El ser humano no puede vivir sin relacionarse, sin consumir, pues tiene cuerpo. Pero la clave está en el cómo de esa relación y consumo, necesarios por naturaleza. No debería ser a costa de olvidar el valor de cada ser en el seno del ecosistema. Y esa integración sugiere precisamente las variantes éticamente aceptables del cómo se puede obtener una relación de provecho. Félix Rodríguez de la Fuente, preguntándose por quién le había causado más profunda impresión en su vida, se descubre respondiendo que Lazabo, un pigmeo de la selva de 
Ituri (actual R. D. del Congo). Cazador de elefantes según un estilo de caza con lanza en el que se juega la vida, una vez cobrada la enorme presa, Félix inquiere por su destino.

- Yo no puedo comer ni guardar nada del elefante que he matado porque Comba [el padre de los elefantes y de los pigmeos y de todas las plantas y animales] me castigaría y me volvería peor que una bestia, pero si otro cazador mata yo sí puedo comer de la carne.

Quedé asombrado ante el prodigio de un hombre primitivo que, después de jugarse la vida para matar a un elefante, cree que no puede comer de él para no apropiarse de algo que pertenece a la naturaleza. (Varillas 2010,410)

Asombra moralmente, y alecciona, este modo de entender la relación con el elefante y con el cosmos, por parte de un cazador del que con frecuencia se observan solamente sus rasgos primitivos. Se entiende por qué Rodríguez de la Fuente situaba en el fin de la vida cazadora y recolectora el origen histórico del impacto ambiental que lamenta el ambientalismo (Puig and Casas 2017). El poder sobre el elefante no convierte al cazador en propietario. Lazabo no renuncia a su caza y muerte para dar alimento a su pueblo. Pero no de cualquier manera: con respeto, gratitud, desprendimiento, equilibrio... sin excesos.

El antropocentrismo destaca en exceso la relación de propio provecho. También en el cristianismo sociológico. Y así el ser humano ejerce un tipo de dominio que jamás se le ha concedido moralmente. ¿Cómo podría el cristianismo ayudar a corregir este enfoque? A muchos cristianos ha inspirado el llamado Sermón de la Montaña, del que se escoge el siguiente párrafo:

Miren los pájaros del cielo: ellos no siembran ni cosechan, ni acumulan en graneros, y sin embargo, el Padre que está en el cielo los alimenta. ¿No valen ustedes acaso más que ellos? [...] ¿Y por qué se inquietan por el vestido? Miren los lirios del campo, cómo van creciendo sin fatigarse ni tejer. [...] Si Dios viste así la hierba de los campos, que hoy existe y mañana será echada al fuego, ¡cuánto más hará por ustedes, hombres de poca fe! (Mt 6, 26-30)

Una lectura antropocéntrica justificaría un dominio humano absoluto sobre lo inferior. Volviendo al punto 1 , se podría replicar que el poder del Creador 
se manifiesta creando el universo, la riqueza de los ecosistemas y de la vida, no consumiéndolos. Con una fidelidad que los mantiene siendo, existiendo como son, ricos y en relación. Así, otra lectura del texto podría ser más fiel a la verdad. Lo avalaría la cultura ambiental, que ayudaría a corregir el antropocentrismo. El creyente debería leer al Creador en lo natural: “... el Padre que está en el cielo los alimenta [...] Dios viste así la hierba de los campos”. Este valor de relación entre naturaleza y Creador enlazaría muy bien, por otra parte, con sabidurías ancestrales como la expresada por Lazabo en el relato de la caza del elefante. En suma, "ninguna cosa natural, ni por tanto la naturaleza, agota su ser en su función” (Ramos 1993, 26). Menos aún en su función para el ser humano: “Todo está conectado. Si el ser humano se declara autónomo de la realidad y se constituye en dominador absoluto, la misma base de su existencia se desmorona” (Francisco 2015, n. 117). Y no solamente la base natural, podría añadirse, sino también la moral (Punto 7).

\section{Porque existe como es, en relación natural conmigo, la naturaleza tiene valor}

El término "mío" puede referirse a lo que me pertenece y con lo que hago lo que quiero, sin tener que rendir cuentas a ningún respeto debido. El objeto poseído, cosa, carecería de valor propio. Alternativamente, "mío" puede señalar una realidad valiosa a la que pertenezco junto con lo mío; algo superior a los dos, que me enriquece y, por tanto, respeto y quiero. En este sentido, mi hermano no es ni puede ser tratado como una posesión. Ambos pertenecemos a la misma familia, y por esa pertenencia le debo un respeto añadido. La familia es en nosotros, y pertenecer a ella nos enriquece recíprocamente. La familia, vista con una mentalidad compartida con la ecología, es más que la mera suma de los familiares, a los que la existencia de la primera -una relación de pertenencia, no de posesión- enriquece.

Leopold señaló que maltratamos a la tierra porque la vemos como una mercancía que nos pertenece; y que cuando la veamos como una comunidad a la que pertenecemos, tal vez empecemos a usarla con amor y respeto (1966, Prefacio, $\mathrm{x})$. Sería más completo decir que tierra y ser humano se pertene- 
cen, con una pertenencia que no reduce valor a ninguno de los términos recíprocamente pertenecientes, sino todo lo contrario. El ser humano no pertenecería a la tierra de un modo que disuelva su singularidad y aminore o anule su valor específico humano e individual, frente al todo o en el seno de lo natural no humano, como algunos biocentrismos pueden sugerir.

Tierra y ser humano se distinguen y relacionan asimétricamente, porque la naturaleza no humana y el ser natural humano son naturalmente diferentes. Yendo de lo natural a lo humano, el cuerpo testimonia la contundente presencia del ecosistema en el "sí mismo" humano. El cuerpo sería el medio natural en el yo (Puig et al. 2014, 125). Ese aspecto de la identidad enriquece al ser humano, al integrar en él el valor del ecosistema.

Para la antropología no puede valorarse como una casualidad, ni como un dato sin consecuencia moral, que compartamos con la naturaleza no humana la materialidad de átomos, moléculas y genes, tipos celulares y de tejidos, familias de órganos vitales, funciones metabólicas, relaciones ecológicas e incluso no poco de las conductas y sentimientos propios del mundo animal vinculados a nuestra condición natural. (Puig 2016, 124-126)

En reciprocidad, el ser humano aporta también constitutivamente su propio valor a todo lo natural no humano, en relación corporal con él. Esta es una reflexión menos explicitada en el seno de ambientalismo, pero sí intuida por algunos. Si lo natural se integra de tal manera en lo humano, y es también en lo humano, se debe reconocer a lo natural un estatuto acorde; un valor humano que se integra en lo natural a respetar: "Existe entre ser humano y naturaleza un vínculo - que edifica la comunidad natural y humana a la que pertenecemos- que no puede ser obviado sin erosionar el valor de ambos a la vez" (Puig et al. 2014, 128).

El cristianismo puede alimentar esta visión. Yendo desde la naturaleza al ser humano, cuando afirma que "nosotros mismos somos tierra" (LS, n. 2). Yendo desde el ser humano a la naturaleza, cuando afirma que el Hijo de Dios ha incorporado en su persona parte del universo material (Francisco 2015, n. 235). También cuando sostiene que... "El universo se desarrolla en 
Dios, que lo llena todo. Entonces hay mística en una hoja, en un camino, en el rocío, en el rostro del pobre” (Francisco 2015, n. 233).

San Juan de la Cruz enseñaba que todo lo bueno que hay en las cosas y experiencias del mundo «está en Dios eminentemente en infinita manera, o, por mejor decir, cada una de estas grandezas que se dicen es Dios». No es porque las cosas limitadas del mundo sean realmente divinas, sino porque el místico experimenta la íntima conexión que hay entre Dios y todos los seres, y así «siente ser todas las cosas Dios». (Francisco 2015, n. 234)

Una figura de esa armonía y pertenencia recíproca la aporta la predicación de Francisco de Asís a los pájaros, atentos a su palabra (Celano 2019, n. 58).

\section{Porque existe como es, en relación natural conmigo y con todos los demás seres humanos, la naturaleza tiene valor}

Llenar el depósito del vehículo puede estar en relación con un daño ejercido a miles de kilómetros. Así, Chevron ha sido acusada de daños ambientales y sociales causados por su explotación de petróleo en Ecuador. La globalización encierra comportamientos que no aceptarían ni como enunciado quienes pueden practicarlo, sin embargo, más o menos inadvertidamente: "Sea para mí el beneficio (del petróleo) y para otros la destrucción que puede causar que yo lo use”. El progreso concreto, tal y como se ha dado históricamente, ha sido denunciado por su inequidad, por ejemplo, desde notables figuras del ecofeminismo (Shiva 2014, 142).

La sensibilidad ambiental integra los problemas de inequidad social, incluyendo a las indefensas generaciones futuras. No es fácil aceptar que el bienestar de unos pueda estar tan ligado al daño que otros sufren o sufrirán. Estas conexiones no ocurren aisladamente, restringidas al consumo de gasolina. Ocurren con el consumo de ropa, de productos alimentarios, ... o con el exceso mismo de consumo. Crece la consciencia de que la riqueza natural, compartida o compartible, acarrea una responsabilidad social inseparable de la ambiental: "Dependemos de la tierra y, a través de ella, 
nos relacionamos con los demás y les afectamos (por acción u omisión) mediante los sistemas sociales y económicos construidos, sustentados en los bienes que nos da y distribuimos." (Puig 2016, 124)

La articulación de estas dos sensibilidades -social y ambiental, hechas una sola- es un rasgo destacado de la encíclica Laudato si' (Francisco 2015 , nn. 16 y 49). Desde una perspectiva cristiana, «Dios ha dado la tierra a todo el género humano para que ella sustente a todos sus habitantes, sin excluir a nadie ni privilegiar a ninguno» (Juan Pablo II, 1991). Nadie sensato admite la exclusión como principio, por más que sea una realidad de hecho, practicada a escala internacional con manifestaciones notorias, como la de tantas fronteras insolidarias, en especial entre mundo materialmente rico y mundo pobre. Pero según la segunda parte de la afirmación se debería revertir además el privilegio de hecho existente en el uso de la tierra. C.S. Lewis en otro contexto - pero que puede ser integrado aquí con un sentido propio, que no traicione el original, sino que lo despliegue- ya apuntaba este privilegio:

Lo que llamamos el poder del Hombre [sobre la naturaleza] es, en realidad, un poder que poseen algunos hombres, que pueden permitir o no que el resto de los hombres se beneficien de él. [...] lo que llamamos el poder del Hombre sobre la Naturaleza se revela como un poder ejercido por algunos hombres sobre otros con la Naturaleza como instrumento. (Lewis 1943, 25-26)

La cita de Juan Pablo II invitaría a que cada uno ponga su posible privilegio al servicio de quienes no lo disfrutan, encaminándolo a desaparecer en forma de mayor beneficio común: "El principio de la subordinación de la propiedad privada al destino universal de los bienes y, por tanto, el derecho universal a su uso es una «regla de oro» del comportamiento social y el «primer principio de todo el ordenamiento ético-social» (Francisco 2015, n. 93).

Parece mucha exigencia para una sociedad caracterizada por un bienestar apoyado en el consumo. Todo impulsa a limitar el consumo más por la finitud de la propia economía que por sentir una llamada a compartir, la cual no parece tan arraigada culturalmente como lo está el consumo de lo superfluo. Se ha señalado desde el Cristianismo Ortodoxo que difícilmente habrá solución a la crisis ambiental sin sacrificio voluntario del propio bienestar: 
Al igual que la cura del corazón y la construcción de la paz, la consciencia ecológica también demanda una conversión o metanoia: un cambio en los hábitos y estilos de vida. Paradójicamente, llegamos a ser más conscientes del impacto de nuestras actitudes y acciones sobre otra gente y el medio ambiente natural cuando estamos dispuestos a entregar algo. Esta es la razón por la que ayunar es un aspecto crítico de la disciplina Cristiana Ortodoxa: aprendiendo a renunciar, aprendemos gradualmente a dar. $\mathrm{Al}$ aprender a sacrificarnos, aprendemos a compartir. Desafortunadamente, tantos esfuerzos nuestros hacia la reconciliación -sea espiritual, social o ecológica-son infructuosos en parte porque no estamos dispuestos a abstenernos de caminos bien establecidos individual o institucionalmente, y rechazamos la renuncia al consumismo despilfarrador o al nacionalismo orgulloso. (Bartholomew 2003, 334)

No se trataría de renunciar por renunciar, sino para no causar daño o para beneficiar a terceros, incluida la tierra, con un bien superior al provecho personal al que se renuncia. "Menos es más" (Francisco 2015, n. 222), propone Francisco, adaptando junto con el ambientalismo y hacia la solidaridad el sentido original que se atribuye a esta frase.

La cultura contemporánea, pese al ideal de fraternidad universal, parece empujar en sentido opuesto. Subraya desde hace siglos como objetivo el propio bienestar material, y aminora la percepción de otros bienes superiores de carácter moral y colectivo. Se da incluso por hecho como inevitable que enriquecerse cause algún daño, como si fuera natural. En este sentido, afirmaba Aldo Leopold lo siguiente: "Nuestras herramientas son mejores que nosotros y mejoran más rápidamente. Permiten romper los átomos y disponer de las mareas, pero no bastan para la tarea más antigua de la historia humana: vivir de un pedazo de tierra sin estropearla” (Leopold, 1938, 410)

El ejemplo de Yacouba Sawadogo (Punto 2) cuestiona frontalmente este modo de ver las cosas y de vivir. Lo propio del ser humano, naturalmente inteligente y moral, sí sería enriquecerse. Pero enriqueciendo siempre a los demás y a la tierra, en todo tiempo y lugar. Se podría alimentar esta propuesta, desde una perspectiva cristiana, interpretando los milagros de la multiplicación de los panes y de los peces narrados en el evangelio 
según Mateo 14:13-21 y 15:32-39. Parecen sugerir que, por naturaleza, el ser humano está llamado a multiplicar y dar, no a agotar ni a acopiar, que viene siendo -al menos históricamente- la vía fácil para el enriquecimiento material desigual o excluyente que beneficia a menos de los que perjudica.

\section{Porque existe como es, en relación natural conmigo y con todos los demás seres humanos, la naturaleza tiene valor, material}

Todos los aspectos del valor natural que se vienen tratando se encuentran, en la realidad, reunidos. A partir de aquí se recapitula lo dicho resumiéndolo en los valores material y moral (Punto 7) de lo natural. Podría pensarse que la dimensión material del valor natural no se pierde de vista en una sociedad consumista. Ciertamente, se ve fácilmente en la materialidad de los seres naturales un valor material. Pero se tiende a no captar todo su valor material. Sucede así, por ejemplo, cuando se reduce el valor de la materia, su valor material pleno, al de un (mero) material.

La materia tiene un valor propio. Se puede justificar así, de entrada, porque existe como tal (Punto 1). Un material, en cambio, es aquél cuyo valor no se le reconoce como algo propio, porque existe, sino por su utilidad para un fin, que es el que le otorga su valor como material: es una simple posesión (Punto 4). Las ciencias de lo natural pueden haber promovido sin quererlo, incluso prevalentemente, ver el mundo como un material a las órdenes de la capacidad técnica de aprovecharlo. Pero la ciencia está acompañada, desde su origen, de un impulso de curiosidad, de una llamada misteriosa, atrayente, que parece nacer en la realidad material misma, y se resiste vocacionalmente a reducir su desempeño al de la instrumentalización del mundo, a la que se refería Macfarlane (2016) en el Punto 1. El científico, que en muchos casos se identificaría como materialista, puede sin embargo experimentar personalmente que, una vez las ciencias experimentales han dicho todo lo que está en su plano decir, queda mucho más por decir sobre el medio ambiente (Shairp 1877, v-vi). 
Este materialismo profundo, por llamarlo de alguna manera, podría ayudar a los creyentes a no caer en un dualismo que quieren evitar al referirse al ser humano y el mundo natural, según el cual, cuerpo y alma no constituirían una íntima unidad o realidad, la de cada persona. El materialismo profundo vería la misma realidad que un creyente, la cual es en parte inasible e inefable. Sería consciente del misterio del arte en la materia, por ejemplo. Pero se resistiría a reconocer o hablar de algo sobre-material al referirlo, para no rebajar un valor (en la materia, íntimo a ella) que ve con lucidez. El materialismo se opondría a hablar de que el valor de la materia no esté en ella misma. Con esa materia sentiría incluso entrar en comunión, experiencia muy propia del ambientalismo. Materia, desde ese acercamiento profundo, no sería por tanto solamente lo detectable con las ciencias experimentales, pese a que ellas son de hecho las que más influyen en el significado atribuido a la materia que domina hoy.

Uno de los sobrescritos, en catalán, que se puede leer en la obra de Tàpies titulada "L’Esperit Català"1 es el siguiente: "Espiritualitat = materialisme". Con independencia de que las palabras no pueden encerrar su plasticidad en la obra de arte, y del desconocimiento del alcance de la posible intencionalidad de su autor o del lenguaje propio de la obra misma, bien puede esta obra ofrecer un ámbito de diálogo entre materialismo y espíritu, creyente o no.

La vivencia del mundo natural por el ambientalista que expande su experiencia más allá de lo que puede decir la ciencia experimental es compartida crecientemente (Mallarach 2013, 30-31). En el seno de la materialidad de la naturaleza, y al experimentarla personalmente, el ambientalismo intuye y subraya un valor inalcanzable para las ciencias experimentales. Está, sin embargo, presente en las experiencias personales de comunión, tan cercanas al romanticismo que cuestionó los excesos mecanicistas, como el de Malebranche (Punto 2). La intuición de ese valor trans-científico en la materia, que no aceptaría el materialismo cientificista, invita a muchos a contemplar un misterio valioso que anidaría en el corazón de la materia y le otorgaría valor, siéndola. Un misterio difícil de asir, pero cuyos efectos

1 https://museo.unav.edu/coleccion/la-coleccion/esperit-catala 
son notorios en el espíritu humano: "La Naturaleza nos vuelve humildes, nos enseña el lugar que tenemos dentro del cosmos, nuestra fragilidad y dependencia permanente de innumerables seres vivientes, tantos que apenas podemos concebir, y sin los cuales no podríamos subsistir ni un sólo día.” (Mallarach 2013, 31)

En este punto el cristianismo ofrece un nuevo encuentro en la cultura ambiental. El misterio apuntado podría enlazar con el Misterio encarnado del creyente. Dios escoge hacerse material, diría el cristiano (Punto 4). La incredulidad de Santo Tomás, de Caravaggio (Figura 3) ofrece una posibilidad inagotable de considerarlo y contemplarlo, a través de la expresiva averiguación con la que Tomás repliega la carne de Jesús resucitado, al introducir inquisitivamente su dedo en el costado abierto en la Cruz. En continuidad con lo mencionado, Francisco (2015, n. 235) recuerda que el cristianismo no rechaza la materia, la corporeidad, sino al contrario: "El Señor, en el colmo del misterio de la Encarnación, quiso llegar a nuestra intimidad a través de un pedazo de materia. No desde arriba, sino desde adentro, para que en nuestro propio mundo pudiéramos encontrarlo a él” (Francisco 2015, n. 236).

\section{Porque existe como es, en relación natural conmigo y con todos los demás seres humanos, la naturaleza tiene valor, material y moral}

¿Por qué consumir menos, usar transporte público, comprar productos ecológicos, mantener la casa a una temperatura ni excesivamente cálida ni excesivamente refrigerada, hacer donativos anónimos, etc. si el cambio individual no va a mejorar la calidad ambiental y social, vista a escala mundial? Se tiende a valorar el compromiso y la conducta, preferentemente, por el efecto tangible que causan en la escala a la que se desearía que fueran notables. La cultura en su conjunto empuja a olvidar la realidad y el valor de lo intangible. Pero a esa clase intangible pertenece el cambio moral, la raíz acaso más poderosa de todo cambio tangible. El cambio moral es siempre un fenómeno primariamente personal y solo se verificable tangiblemente 
a posteriori, en un cambio de conducta. Es posible que, en el caso de que se extendiera al conjunto de la sociedad ese cambio moral intangible -personal, en cada persona- después cambiara la cultura, más que al revés. También en lo ambiental.

Aldo Leopold cuenta, treinta años después del suceso, la impresión que le causó la mirada de una loba moribunda a la que poco antes había disparado desde la lejanía. El suceso se revelaría, a la larga, de enorme significación moral profesional y social (Puig and Echarri 2018), precipitando un sustantivo empuje al nacimiento de la Ecología de la Restauración, la Biología de la Conservación y la Ética Ambiental, nada menos. Al acercarse a la loba, Leopold $(1966,130)$ llegó a tiempo de ver el feroz fuego verde que moría en sus ojos. En ese momento se percató de algo que supo desde entonces. Leopold se retrata a sí mismo, hasta ese momento, como un joven con ganas de apretar el gatillo que se figuraba que, como menos lobos significaban más ciervos, la eliminación de los primeros llevaría al paraíso del cazador. Pero tras ver morir aquel fuego, percibió que ni la loba ni la montaña estaban de acuerdo con él. Había descubierto un nuevo valor. Misterioso. Le llevó décadas ir desplegando sus implicaciones, y dejar de promover al fin -por ejemplo- la caza del lobo que su propia ciencia mostró como una intervención dañosa no solamente para los lobos, sino para enteros ecosistemas.

El descubrimiento de un nuevo valor de entidad -un suceso intangiblesuele conllevar un conflicto para la conducta de la persona en la que irrumpe. Puede exigir un cambio en sus hábitos, renuncias incluso (Bartholomew 2003, 334). Una cultura centrada en exceso en lo tangible difícilmente sabrá renunciar a nada por algo intangible, pues en la renuncia prevalecerá un sentido de pérdida. Sobrevalorar lo tangible empuja más a disfrutar los beneficios del consumo que a enriquecerse con una privación escogida de lo innecesario que posibilita apreciar valores mayores, o ser más coherentes y solidarios. El vínculo entre cada persona, el ecosistema y la sociedad no es sólo material. Es también moral (Puig et al. 2014, 123-124). Cada elección que afecta tangiblemente al ecosistema o a la sociedad cambia a la vez el yo moral intangible, que es real: al hacer daño ambiental o social, el individuo se daña moralmente; y al enriquecer el medio ambiente o a los 
demás materialmente, se enriquece moralmente (Puig 2016, 115). Una mala conducta moral daña ese vínculo. Y así se desintegra a la vez lo material y lo intangible y moral de la persona y su medio ambiente.

Valorar lo intangible moral facilitaría la renuncia, cuando se viera como una ganancia moral. La supuesta renuncia dejaría de ser vista negativamente y posibilitaría modos de relación más valiosos (e incluso más valorados subjetivamente) que los de la posesión o disfrute tangible, como la generosidad. Volviendo a la pregunta inicial de este apartado, la respuesta podría ser: "porque esa decisión cambia a mejor, precisamente, el sí mismo de quien la toma”. Y ese es posiblemente el cambio más radical, valioso y al alcance de la propia decisión y libertad que cada cual tiene en su mano posibilitar. El cambio personal en pequeños compromisos que no parecen cambiar todavía el mundo a escala planetaria ya merece la pena. El cristianismo es consciente de la dimensión moral del valor y de la conversión ambiental, por modestos que sean, y los promueve junto con el ambientalismo:

La educación en la responsabilidad ambiental puede alentar diversos comportamientos que tienen una incidencia directa e importante en el cuidado del ambiente, como evitar el uso de material plástico y de papel, reducir el consumo de agua, separar los residuos, cocinar sólo lo que razonablemente se podrá comer, tratar con cuidado a los demás seres vivos, utilizar transporte público o compartir un mismo vehículo entre varias personas, plantar árboles, apagar las luces innecesarias. Todo esto es parte de una generosa y digna creatividad, que muestra lo mejor del ser humano. El hecho de reutilizar algo en lugar de desecharlo rápidamente, a partir de profundas motivaciones, puede ser un acto de amor que exprese nuestra propia dignidad. (Francisco 2015, n. 211)

\section{Conclusión}

Porque existe como es, en relación natural conmigo y con todos los demás seres humanos, la naturaleza tiene valor, material y moral. Así se podría presentar la primera conclusión, desarrollada en los apartados precedentes. Se ha procurado desglosar en siete puntos los aspectos del valor que, y esta sería la segunda conclusión, solicitan un compromiso y, en su medida, una conversión de las conductas desde su corazón moral. 
Además, la conversión de las conductas se propone y justifica como un lugar propicio para el diálogo entre medio ambiente y cristianismo. $O$ entre ambientalismo y cultura dominante. La conversión propia sería la expresión y disposición más plena al encuentro y al respeto natural y social, que exige respetar lo encontrado. Y esta sería la tercera conclusión.

Por último, del grado con que ese encuentro se dé puede depender la misma existencia de muchos valores ambientales, naturales y sociales. También la siempre necesaria unidad entre los seres humanos en la Tierra. E incluso, desde la perspectiva cristiana, el plan de Dios para su creación, a cuyo destino ha ligado indisociablemente el de los seres humanos. De ahí esta urgencia: “[...] algunos cristianos [...] suelen burlarse de las preocupaciones por el medio ambiente. Otros son pasivos, no se deciden a cambiar [...]. Les hace falta entonces una conversión ecológica, que implica dejar brotar todas las consecuencias de su encuentro con Jesucristo en las relaciones con el mundo que los rodea (Francisco, 2015, n. 217).

\section{Bibliografía}

1080 Film \& Television 2012. What Yacouba did next... Accessed March 8. https:// www.youtube.com/watch?v=wezxNnkcsW8.

Bartholomew I. 2003. In: Cosmic grace, humble payer: the ecological vision of the green patriarch Batholomew. Edited by John Chryssavgis. Cambridge, UK: Wm. B. Eerdmans Publishing Co.

Benedicto XVI. 2009. Audiencia General 26 de agosto.

Carson, Rachel. 2012. El sentido del asombro. Madrid: Ediciones Encuentro, S.A. CBD 2019. Convention on Biological Diversity. Accessed March 6. https://www.cbd.int/ Celano, Tomás de 2019. Vida primera de San Francisco. Accessed March 6. http:// www.franciscanos.org/fuentes/1Cel03.html

COP10 2011. United Nations Convention to Combat Desertification. Accessed March 6. https://www.unccd.int/official-documents/cop-10-changwon-2011

Francisco. 2015. Carta Encíclica LAUDATO SI' del Santo Padre Francisco sobre el Cuidado de la Casa Común.

IUCN. 2019a. About. Accessed March 6. https://www.iucn.org/about

IUCN. 2019b. Commission on Environmental, Economic and Social Policy. Religion, Spirituality, Environmental Conservation and Climate Justice. Accessed March 6. https://www.iucn.org/es/node/514 
Juan Pablo II. 2001. Audiencia General 17 de enero.

Juan Pablo II. 1991. Carta encíclica Centesimus annus del sumo pontífice en el centenario de la Rerum Novarum.

Lewis, Clive Staples. 1943. La abolición del hombre. Accessed March 6. http://ciudadanoaustral.org/biblioteca/05.-C.S.-Lewis-La-abolicio\%23U0301n-del-hombre.pdf Leopold, Aldo. 1966. A Sand County Almanac, with other essays on conservation. Oxford University Press, New York.

Leopold, Aldo. 1938. “Engineering and Conservation.” In Aldo Leopold. A Sand County Almanac and other Writings on Ecology and Conservation. Edited by Curt Meine. 2013. New York: Library of America, 405-410.

Mallarach, Josep Maria. 2013. “Más allá de la interpretación: conectando en profundidad con la Naturaleza." Europarc-España. Revista técnica de los espacios naturales y protegidos. 36, 30-33.

Macfarlane, Robert. 2016. Landmarks. Penguin Random House, UK.

Muir, John. 2019. My first summer in the Sierra. Sierra Club. Accessed March 6. https:// vault.sierraclub.org/john_muir_exhibit/writings/my_first_summer_in_the_sierra/ chapter_6.aspx

Puig, Jordi; Echarri, Fernando and Casas, María. 2014. "Educación ambiental, inteligencia espiritual y naturaleza.” Teoría de la Educación. 26, 2: 115-140.

Puig, Jordi. 2016. "Un ambientalista se encuentra con encíclica Laudato si’. Una llamada (¿inesperada?) a la conversión desde la ecología.” In Cuidar la creación. Estudios sobre Laudato si', edited by Tomás Trigo. 113-151. Pamplona: Ediciones Universidad de Navarra, S.A.

Puig, Jordi and Casas, María. 2017. "El impacto ambiental: un despertar ético valioso para la educación.” Teoría de la Educación. 29, 1: 101-128.

Puig, Jordi and Echarri, Fernando. 2018. "Environmentally significant life experiences: the look of a wolf in the lives of Ernest T. Seton, Aldo Leopold and Félix Rodríguez de la Fuente.” Environmental Education Research, 24, 5: 678-693.

Ramos, Ángel. 1993. ¿Por qué la Conservación de la Naturaleza? Madrid: Fundación Conde del Valle de Salazar.

Scheuering, Rachel White. 2004. Shapers of the great debate on conservation. A biographical dictionary. Westport, CT, USA: Greenwood Press.

Shairp, John Campbell. 1877. On poetic interpretation of nature. Edinburgh: David Douglas.

Shiva, Vandana. 2014. "El empobrecimiento del medio ambiente: las mujeres y los niños, los últimos.” In: Ecofeminismo, edited by Maria Mies and Vandana Shiva. Barcelona: Icaria editorial. 141-170.

Spaemann, Robert. 1989. Lo natural y lo racional. Madrid: Ediciones Rialp. 
United Nations. 2019. The man who stopped the desert. Accessed March 8. http:// webtv.un.org/watch/the-man-who-stopped-the-desert/5240814596001/?ter$\mathrm{m}=$ \&lan=english

United Nations. 2019b. Global Environmental Outlook. Accessed March 11. https:// www.unenvironment.org/global-environment-outlook

Varillas, Benigno. 2010. Félix Rodríguez de la Fuente. Su vida, mensaje de futuro. Madrid: La Esfera de los libros, S.L.

Watson, Richard A. 2002. Cogito, Ergo Sum. The life of René Descartes. Boston: David R. Godine, Publisher.

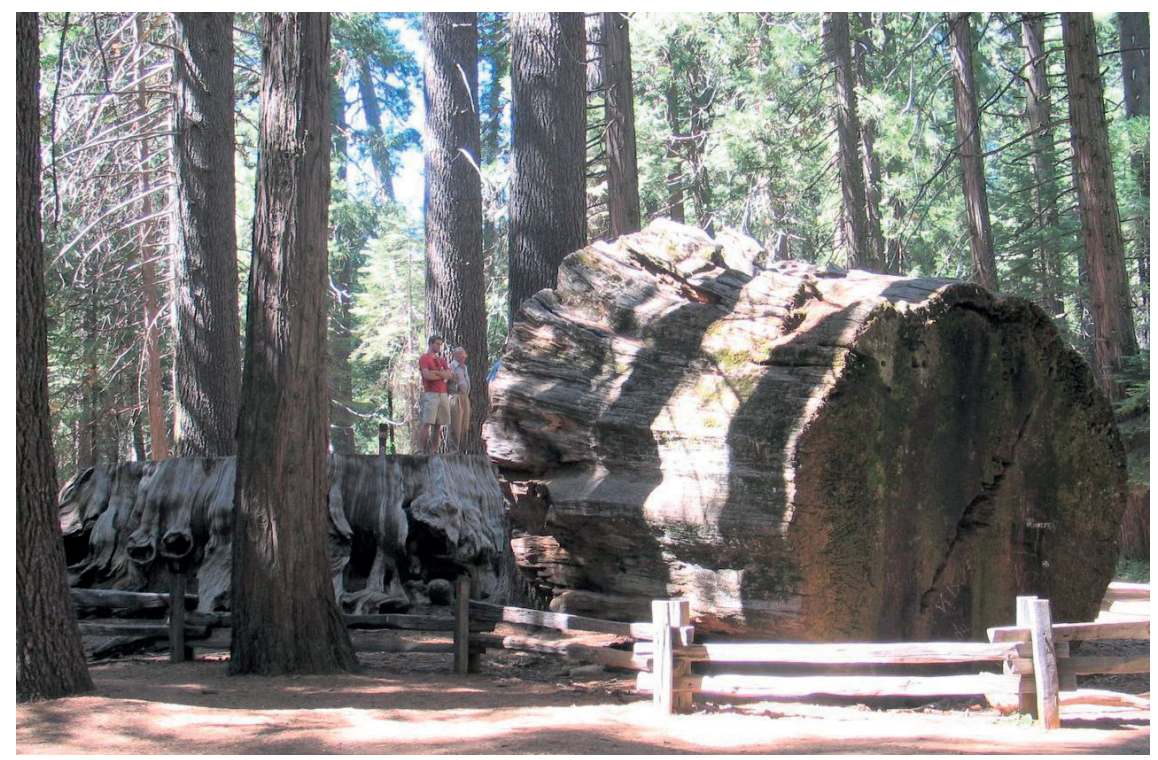

Figura 1. El Discovery Tree, en Calaveras Big Trees State Park, California, USA Fuente: Wikimedia commons. https://commons.wikimedia.org/w/index. php?search=discovery+tree+calaveras \&title=Special\%3ASearch\&go=Go\#/ media/File:DiscoveryTree1.jpg 


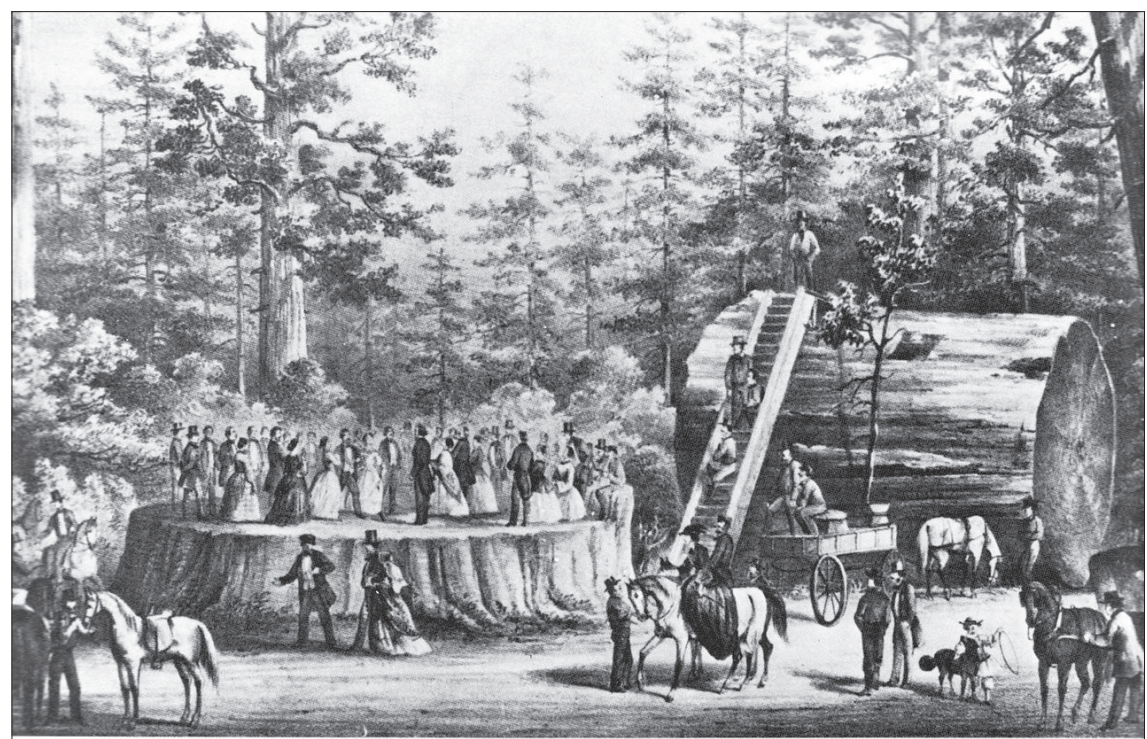

THE STUMP ano TRUNK or the MAMMOTH TREE of calaveras.

Showing" Clillion Parly of Thirlytno Persens Dancing on the Sillmp al ine lim!

Figura 2. El Discovery Tree, plataforma de baile

Fuente: Wikimedia commons. https://commons.wikimedia.org/w/index. php? search=discovery+tree+calaveras \&title=Special\%3ASearch\&go=Go\#/ media/File:Giant_sequoia_exhibitionism_(cropped).jpg 


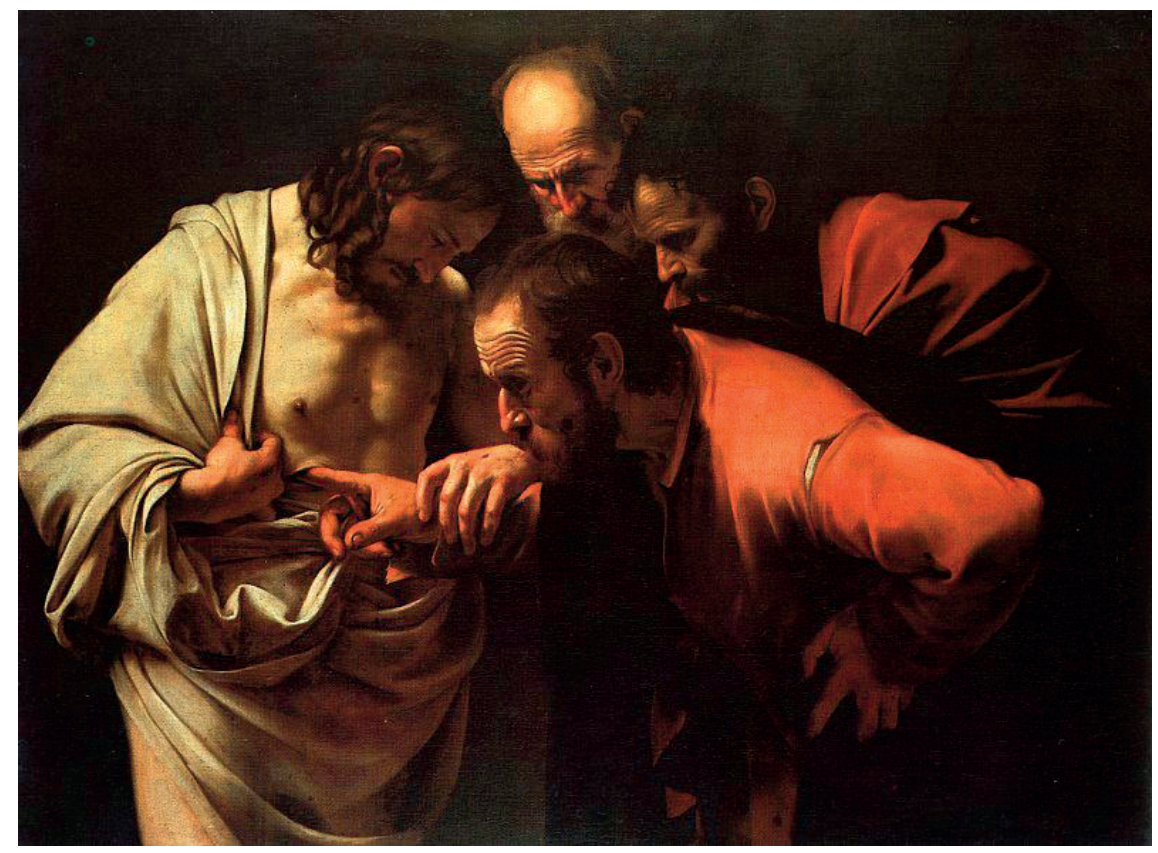

Figura 3. La incredulidad de Santo Tomás. Caravaggio

Fuente: Wikimedia commons. https://commons.wikimedia.org/w/index. php?search=caravaggio+thomas \&title=Special\%3ASearch \&go=Go\#/media/ File:Caravaggio_-_The_Incredulity_of_Saint_Thomas.jpg 